\title{
Magnetic Properties in $\mathrm{Ba}_{2} \mathrm{YCu}_{3} \mathrm{O}_{7-x}, \mathrm{Ba}_{2} \mathrm{DyCu}_{3} \mathrm{O}_{7-x}$ and $\mathrm{Ba}_{2} \mathrm{HoCu}_{3} \mathrm{O}_{7-x}$
}

\author{
Yoshiki TAKAGI, Ruixing LIANG, Ryozo AOKI* and Tetsurō NAKAMURA \\ Research Laboratory of Engineering Materials, Tokyo Institute of Technology \\ 4259, Nagatsuta-cho, Midori-ku, Yokohama-shi 227 \\ * Department of Physics, Kyushu University, 6-10-1, Hakozaki, Higashi-ku, Fukuoka-shi 812
}

\section{$\mathrm{Ba}_{2} \mathrm{YCu}_{3} \mathrm{O}_{7-x}, \mathrm{Ba}_{2} \mathrm{DyCu}_{3} \mathrm{O}_{7-x}$ および $\mathrm{Ba}_{2} \mathrm{HoCu}_{3} \mathrm{O}_{7-x}$ の磁気的性質}

\author{
高木喜樹·梁 瑞興・青木亮三*・中村哲朗 \\ 東京工業大学工業材料研究所, 227 横浜市緑区長津田町 4259 ) \\ * 九州大学理学部物理学科, 812 福岡市東区箱崎 6-10-1
}

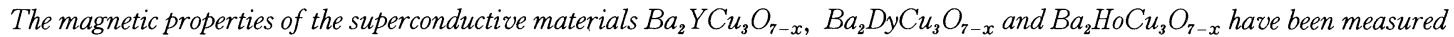
and discussed. Each material had superconductive transition temperatures $T_{\mathrm{c}}$ in the zero magnetic field near $90 \mathrm{~K}$. The magnetic susceptibilities at the liquid nitrogen temperature of the Ho and Dy based materials extrapolated from normal conductive state were very near those of being extrapolated to the high magnetic field on the magnetization curves. This result suggests that the magnetic and superconductive properties independently coexist in this materials.
\end{abstract}

[Received November 25, 1987 ; Accepted January 22, 1988]

Key-words : Superconductor, Magnetization, Density of state

\section{Introduction}

In the traditional metallic superconductors, superconductive states are easily destroyed with magnetic impurities. But in $\mathrm{Ba}_{2} \mathrm{YCu}_{3} \mathrm{O}_{7-x}$ superconductor, if nonmagnetic $\mathrm{Y}$ was substituted by trivalent rare-earth ion, e.g., Eu, Gd, Ho, etc., the resulting materials were still superconductive with $T_{\mathrm{c}}$ values near $90 \mathrm{~K}$. Since local magnetic moments are normally quite effective superconductive pair breakers, this observation implies that the pairs effectively avoid the layers containing rare-earth elements ${ }^{1-3)}$ or that the filled electron band protects the Cooper pairs in conduction band in $\mathrm{Cu}-\mathrm{O}$ molecular orbitals. ${ }^{4), 5}$

\section{Experimental aspects}

The samples investigated were synthesized by reaction and sintering of cold-pressed pellets. To begin, appropriate amounts of $\mathrm{Y}_{2} \mathrm{O}_{3} \quad\left(\mathrm{Dy}_{2} \mathrm{O}_{3}\right.$, $\left.\mathrm{Ho}_{2} \mathrm{O}_{3}\right), \mathrm{Ba}\left(\mathrm{NO}_{3}\right)_{2}$, and $\mathrm{CuO}$ powders were thoroughly mixed and placed in an alumina crucible. The powder was fired at $1173 \mathrm{~K}$ for $12 \mathrm{~h}$ in air and then reground. The entire firing and grinding process was repeated two times to ensure completely homogeneous powder. The prereacted powder was cold-pressed into $1.5 \mathrm{~cm}$ by $0.2-\mathrm{cm}$ thick cylinders and placed in an alumina boat in an atmosphere of flowing oxygen. The pellets were heated and held at $1233 \mathrm{~K}$ for $12 \mathrm{~h}$, then step-wisely annealed, i. e., $1173 \mathrm{~K}$ for $30 \mathrm{~min}$, $1073 \mathrm{~K}$ for $1 \mathrm{~h}, 973 \mathrm{~K}$ for $2 \mathrm{~h}, 873 \mathrm{~K}$ for $4 \mathrm{~h}, 773 \mathrm{~K}$ for $8 \mathrm{~h}, 673 \mathrm{~K}$ for $16 \mathrm{~h}$ and then cooled at $8 \mathrm{~K} / \mathrm{min}$ to room temperature. Powder X-ray diffraction analysis of the resulting ceramics indicated that the material was single phase and of the same structure as $\mathrm{Ba}_{2} \mathrm{YCu}_{3} \mathrm{O}_{7-x}$. The magnetic investigations were performed with magnetic balance (Shimadzu, MB-2H).

\section{Results and discussion}

After cooling to $77 \mathrm{~K}$ in zero magnetic field (ZFC), a flux exclusion (shielding effect) for $\mathrm{Y}$ based material was observed. Figures 1,2 and 3 are plot of the irreversible magnetization of

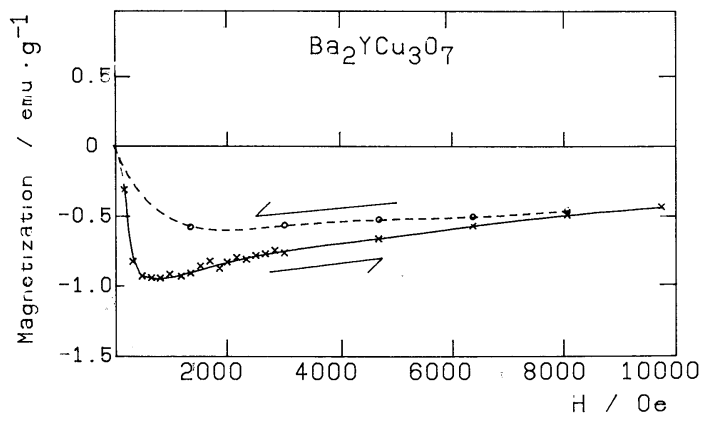

Fig. 1 The magnetization curve in $\mathrm{Ba}_{2} \mathrm{YCu}_{3} \mathrm{O}_{7-x}$ in $77 \mathrm{~K}$. 


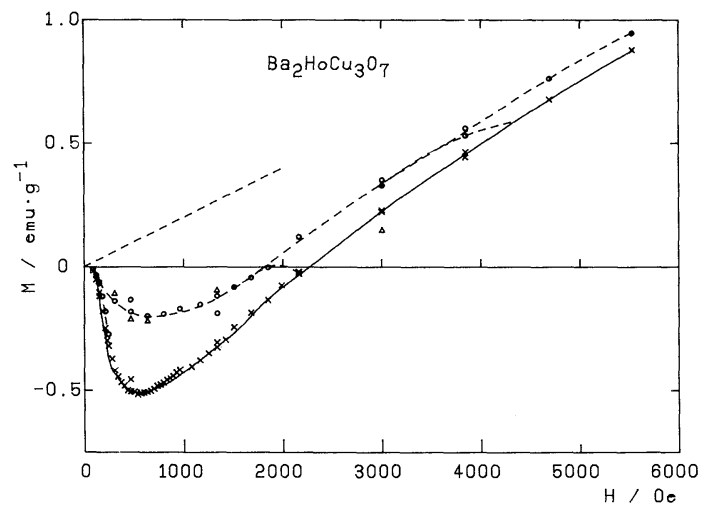

Fig. 2 The magnetization curve in $\mathrm{Ba}_{2} \mathrm{HoCu}_{3} \mathrm{O}_{7-x}$ in $77 \mathrm{~K}$.

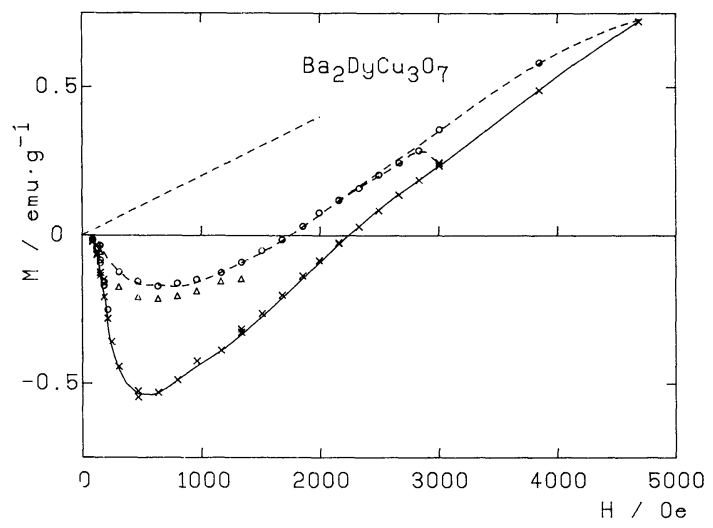

Fig. 3 The magnetization curve in $\mathrm{Ba}_{2} \mathrm{DyCu}_{3} \mathrm{O}_{7-x}$ in $77 \mathrm{~K}$.

$\mathrm{Ba}_{2} \mathrm{YCu}_{3} \mathrm{O}_{7-x}, \mathrm{Ba}_{2} \mathrm{DyCu}_{3} \mathrm{O}_{7-x}$ and $\mathrm{Ba}_{2} \mathrm{HoCu}_{3} \mathrm{O}_{7-x}$ at $77 \mathrm{~K}$, respectively, obtained in increasing and decreasing magnetic field. As the field is increased in virgin state, there is a low-field diamagnetic peak typical of type- II superconductors. Also typical is the hysteresis evident. The gradient of a straight line through origin (dotted line) in Fig. 2 indicates a magnetic susceptibility extrapolated from normal conducting state. The gradient of positive magnetization curve at the higher field (also indicated in Fig. 2), had comparable value being consistent with the extrapolated one. These values are also indicated in Fig. 3. Thus the superconductivity and fieldinduced paramagnetism are occurring quite independently of one another.

The flux exclusions (Meissner effect) observed by cooling to $77 \mathrm{~K}$ in applied magnetic field (FC) are shown in Figs. 2 and 3 as the triangle marks. Since the penetration depth becomes sufficiently short at liquid helium temperature, the observed values of Meissner effect in Figs. 2 and 3 should grow up to the ideal value of diamagnetism at
Table 1 Russell-Saunders coupling, Lande's $g$ value, calculated and observed effective magnetic moments $p_{\text {eff }}$, Weiss's temperatures $\theta$, magnetic susceptibilities $\chi$ extrapolated from normal conductive state and magnetization curve gradient on high magnetic field.

\begin{tabular}{|c|c|c|c|}
\hline & $\mathrm{Ba}_{2} \mathrm{DyCu}_{3} \mathrm{O}_{7-\mathrm{x}}$ & $\mathrm{Ba}_{2} \mathrm{HoCu}_{3} \mathrm{O}_{7-\mathrm{x}}$ & $\mathrm{Ba}_{2} \mathrm{YCu}_{3} \mathrm{O}_{7-\mathrm{x}}$ \\
\hline $\mathrm{RS}$ & ${ }^{6} \mathrm{H}_{15 / 2}$ & ${ }^{5} \mathrm{I}_{8}$ & \\
\hline$g$ & $4 / 3$ & $5 / 4$ & \\
\hline$p_{e f f}(c a l)$ & 10.65 & 10.61 & \\
\hline$p_{e f f}(\exp )$ & 11.45 & 11.49 & \\
\hline$\theta(\exp )$ & -26 & -19 & 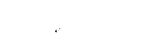 \\
\hline$x(e x t r)$ & $2.06 \times 10^{-4}$ & $2.05 \times 10^{-4}$ & $1.06 \times 10^{-6}$ \\
\hline$\chi(M-H)$ & $3.1 \times 10^{-4}$ & $2.6 \times 10^{-4}$ & \\
\hline
\end{tabular}

liquid helium temperature.

Magnetic susceptibility can be written in the Curie-Weiss form

$$
\chi=\chi_{\mathbf{p}}+C /(T-\theta)
$$

where $\chi_{\mathbf{p}}$ is temperature independent term (Pauli's paramagnetism), $\theta$ is Weiss temperature. For Dy and Ho based materials, $\chi_{\mathrm{p}}$ is relatively small compared to Dy and Ho paramagnetism. But for $Y$ based material, $\chi_{p}$ is not negligible. $\chi_{\mathrm{p}}$ was obtained by extrapolation on $\chi$ vs. $1 / T$ plot, as $\chi_{\mathrm{p}}=3.0 \times 10^{-4} \mathrm{emu} / \mathrm{g}$ per $\mathrm{Cu}$ ion for $\mathrm{Ba}_{2} \mathrm{YCu}_{3} \mathrm{O}_{7}$. This value leads $N(0)$, the density of states at Fermi level, as 16.5 states/eV $\mathrm{Cu}$-atom. The estimated density of states $N(0)$ is sufficiently higher than that of $\mathrm{A}-15^{6)}$ or Chevrel phase compounds ${ }^{7)}$ having superconductive transition temperatures $T_{\mathrm{c}}$ ranging from 10 to $20 \mathrm{~K}$.

We obtain the values of $p$, the effective moment per rare-earth ion present in the sample, as 11.45 B. M. for Dy and 11.49 B. M. for Ho, respectively. These experimental results agree rather well with the value 10.65 and 10.61 B. M. calculated for $f^{9}{ }^{6} H_{15 / 2}$ (Dy) and $f^{10}{ }^{5} I_{8}$ (Ho), respectively. These values were listed in Table 1. In addition, the fitting procedure yields the values of Weiss temperature $\theta,-26 \mathrm{~K}$ for Dy and $-19 \mathrm{~K}$ for Ho. Here the negative sign corresponds to the presence of antiferromagnetic interactions between Dy-Dy and Ho-Ho moments.

\section{References}

1) J.R. Thompson, S. T. Sekula, D. K. Christen, B. C. 
Sales, L. A. Boatner and Y.C. Kim, Phys. Rev., B36, 718-21 (1987).

2) J.R. Thompson, D. K. Christen, S. T. Sekula, B. C. Sales and L. A. Boatner, Phys. Rev., B 36, 836-39 (1987).

3) J. M. Tarascon, W. R. McKinnon, L. H. Greene, G. W. Hull and E. M. Vogel, Phys. Rev., B36, 226-34 (1987).
4) T. Nakamura and R. Liang, Jpn. J. Appl. Phys., 26, L 678-81 (1987).

5) T. Nakamura and R. Aoki, Report RLEMTIT, No. 13 (1988).

6) G. R. Stewart, B. Cort and G. W. Webb, Phys. Rev., B24, 3841-46 (1981).

7) Ф. Fisher, Appl. Phys., 16, 1-28 (1978). 